\title{
PACTO DE ESTABILIDAdE E CRESCIMENTO NA UNIÃO EUROPÉIA: HÁ INCENTIVOS AO SEU CUMPRIMENTO?
}

\author{
Fernando B. Meneguin ${ }^{\S}$ \\ Maurício S. Bugarin
}

\section{RESUMO}

O objetivo deste estudo é analisar, com o instrumental da teoria dos jogos, os incentivos que podem levar um Estado-membro da União Européia a descumprir o Pacto de Estabilidade e Crescimento (PEC) e, assim, manter um déficit excessivo, mesmo sabendo do risco político e financeiro associado ao descumprimento. São analisados vários jogos: informação completa e incompleta entre um país e a União Européia e informação incompleta entre o bloco e dois países. Esse último caso leva a um equilíbrio com construção de reputação. A principal conclusão do trabalho é que o bloco econômico deve ser intransigente e exigir o cumprimento dos acordos pactuados, pois, do contrário, incentivará um descumprimento em cascata do PEC, o que pode inviabilizar a União Econômica e Monetária.

Palavras-chave: União Européia, Pacto de Estabilidade e Crescimento, teoria dos jogos, déficit excessivo.

\begin{abstract}
The objective of this paper is to present a game theory analysis of the incentives a state member of the European Union may have to disrespect the Stability and Growth Pact (SGP), thus keeping an excessive deficit, in spite of the political and financial risks associated with the non-compliance. Several games are analyzed: complete and incomplete information between a country and the European Union and incomplete information between the Union and two countries. This last case brings about an equilibrium that involves reputation building. The main conclusion is that the European Union must be strong and enforce the pact's sanctions, even if that imposes a high political cost. Indeed, if the European Union lacks the determination to compel the members to adjust their deficits, one may expect a general non-compliance of the SGP, which will lead to a fiscal collapse of the Economic and Monetary Union.
\end{abstract}

Key words: European Union, Stability and Growth Pact, game theory, deficit.

JEL classification: C72, F02, H62.

$\S \quad$ Senado Federal. E-mail: meneguin@senado.gov.br.

a IBMEC-SP. Endereço para correspondência: Rua Quatá, 300 - Vila Olímpia - CEP 04546-042 - São Paulo - SP. E-mail: bugarin@isp.edu.br.

Recebido em novembro de 2005. Aceito em maio de 2006. 


\section{INTRODUÇÃO}

A década de 1990 marcou uma transformação fundamental na história européia, resultado da conjugação de vários fatores, dentre os quais se destacam o desaparecimento do bloco do Leste e a concretização do projeto do mercado interno único.

Para enfrentar esses desafios, os países europeus procuraram, no plano econômico, criar a União Econômica e Monetária, que surgiu na seqüência lógica do Mercado Único Europeu. No plano político, por meio de uma política comunitária de relações internacionais e segurança comum, iniciou-se um processo que conduzirá à União Política. A junção da União Econômica e Monetária (UEM) com a União Política caminha em direção à União Européia.

Para tanto, várias negociações foram iniciadas em 1991, envolvendo doze países (Alemanha, França, Reino Unido, Itália, Espanha, Bélgica, Holanda, Portugal, Grécia, Irlanda, Dinamarca e Luxemburgo), que culminaram, em 1992, no Tratado da União Européia, hoje conhecido por Tratado de Maastricht.

Relativamente à União Econômica e Monetária, para que funcione plenamente, é crucial que haja uma coordenação ampla da política macroeconômica da Europa. O componente monetário passou a ser conduzido pelo Banco Central Europeu. No que diz respeito à política fiscal, cada Estado-membro desfruta de autonomia. No entanto, mesmo na política fiscal, uma completa independência poderia gerar riscos, como aumento do déficit e da dívida de algum país acarretar pressão sobre a taxa de juros na UEM ou levar a um ambiente inflacionário que afetaria as economias de todos os Estados-membros.

Tendo em vista a necessidade de disciplina fiscal nos países da União Européia, foi assinado o Pacto de Estabilidade e Crescimento (PEC), que visa a atingir uma sólida gestão das finanças públicas na Europa.

O Pacto gera um comprometimento dos países em manter um processo de vigilância orçamentária constante, de forma a evitar déficits superiores a 3\% do PIB. Em caso de fuga da meta, o Estado-membro se obriga a tomar ações corretivas imediatas e a acatar quaisquer sanções impostas pelo Conselho de Ministros das Finanças - ECOFIN -, órgão central de decisão sobre harmonização fiscal.

Sabe-se que existe uma relação forte entre flutuações econômicas e decisões eleitorais de uma população, tópico recorrentemente estudado tanto em economia como em ciência política.

A teoria conhecida como Political Budget Cycle ("ciclos políticos orçamentários" - Rogoff, 1990) focou a estratégia do governante na política fiscal, como a carga tributária, as transferências governamentais e as despesas correntes do governo, concluindo que o governante tende a distorcer a política fiscal, cortando tributos, aumentando transferências e promovendo gastos que tenham visibilidade imediata. Assim, sugere-se uma tendência a descontrole fiscal em períodos eleitorais.

No caso específico da União Européia, mesmo com a adesão ao Pacto de Estabilidade e Crescimento, o governante tem interesse em se perpetuar no poder. Isto pode criar um incentivo para que o governo de algum Estado-membro da União Européia opte por descumprir o Pacto, produzindo um déficit além do limite previsto com vistas ao crescimento econômico e, com isso, obter mais popularidade com a população de seu país.

O objetivo deste trabalho é analisar, por meio da Teoria dos Contratos e da Teoria dos Jogos, os incentivos que podem induzir um Estado-membro da UE a, primeiramente, aderir ao Pacto de Estabilidade e Crescimento (PEC) para, posteriormente, deixar de cumpri-lo, mesmo tendo ciência 
do risco político e financeiro associado ao descumprimento. A modelagem usada neste estudo foi inspirada em Kreps e Wilson (1982) e Milgrom e Roberts (1982).

$\mathrm{O}$ estudo do tema aqui introduzido encontra-se dividido da seguinte maneira. Na seção 2 encontra-se o desenvolvimento do modelo no qual se apreende como os países maximizam sua utilidade. A seção 3, cerne deste estudo, traz o comportamento estratégico da União Européia e dos Estados-membros em várias situações: jogo com informação completa e incompleta entre um país e o bloco e jogo com informação incompleta entre a União Européia e dois Estados-membros. Este último caso coloca em evidência a importância da construção de reputação por parte da União Européia. A seção 4 estende o modelo básico para uma situação em que a União Européia é dividida em dois outros jogadores: Conselho de Ministros e Comissão Européia. Por fim, a quinta seção discute outras possíveis extensões e a seção 6 traz as conclusões do estudo.

\section{O MODELO BÁSICO}

Para analisar os incentivos que podem levar um Estado-membro da União Européia a aderir ao Pacto de Estabilidade e Crescimento (PEC) e, posteriormente, descumpri-lo, primeiramente deve-se conhecer qual seria o gasto ideal dos países pertencentes ao bloco.

Pressupõe-se que cada governo soberano procure gastar o máximo possível. Para tanto, tomese por base o modelo desenvolvido em Werneck (1995), que vislumbra uma forma de calcular o déficit fiscal ótimo dos estados brasileiros. É proposta uma função de utilidade do governo, baseada no montante das despesas agregadas do ente estatal, de forma que a satisfação do estado aumente à medida que pode despender mais. Assim, apresentam-se as seguintes relações adaptadas do modelo de Werneck:

$$
\begin{aligned}
& U=U(G) \\
& G=D-r B+T
\end{aligned}
$$

em que $G$ é a despesa agregada do Estado-membro, $D$ representa o déficit fiscal, $T$ a receita (tributária) total do país, $B$ a dívida interna, $r$ a taxa de juros paga sobre essa dívida e $U$ a função de utilidade do governo, suposta estritamente crescente e estritamente côncava. $\left(U^{\prime}>0, U^{\prime \prime}<0\right)$.

Por sua vez, $r$ é uma função diferenciável, crescente em relação ao déficit do Estado-membro e decrescente relativamente ao quociente receita/dívida, ou seja,

$$
r=r\left(D, \frac{T}{B}\right), \frac{\partial r}{\partial D}>0, \frac{\partial r}{\partial \frac{T}{B}}<0
$$

Conclui-se que, à proporção que o déficit cresce, o país tem que pagar um maior serviço da dívida, o que diminui o montante disponível de recursos para gastos. Dessa forma, o governo terá de se controlar fiscalmente para garantir um nível de déficit $D$ que maximize suas despesas $G$.

O problema de maximização do Estado-membro, de forma a escolher o déficit fiscal que gere a maior despesa agregada possível, pode ser desenhado da seguinte maneira: 


$$
\begin{aligned}
& \underset{D}{\operatorname{Max}} U=U(G) \\
& r . a . \\
& G=D-r B+T \\
& r=r\left(D, \frac{T}{B}\right)
\end{aligned}
$$

Substituindo as restrições na função-objetivo e resolvendo a maximização em $D$, a condição de primeira ordem (CPO) toma a seguinte forma: ${ }^{1}$

$$
\text { B. } \frac{\partial r\left(D, \frac{T}{B}\right)}{\partial D}=1
$$

A interpretação econômica dessa relação implica igualdade entre custo marginal e ganho marginal, já que o lado esquerdo representa o custo adicional com o aumento de uma unidade do déficit $D$ (custo extra com pagamento do serviço da dívida sobre o estoque $B$ devido ao aumento dos juros $r$ ), e o lado direito, o ganho adicional com o aumento de uma unidade da dívida.

Quando a igualdade (1) é atendida, o Estado-membro estará executando um nível de despesa e, conseqüentemente, promovendo um déficit ótimo $D_{o t}$ que faz com que a utilidade do país seja maximizada. O valor desse gasto que otimiza a utilidade do governo é denominado $G_{\max }$. Como $U$ é estritamente crescente, será utilizada nas análises a variável $G$ no lugar de $U(G)$, ou seja, por simplicidade, supõe-se que o nível de utilidade do Estado-membro é exatamente seu nível de gasto líquido.

\section{Figura 1 - Déficit ótimo do Estado-membro}

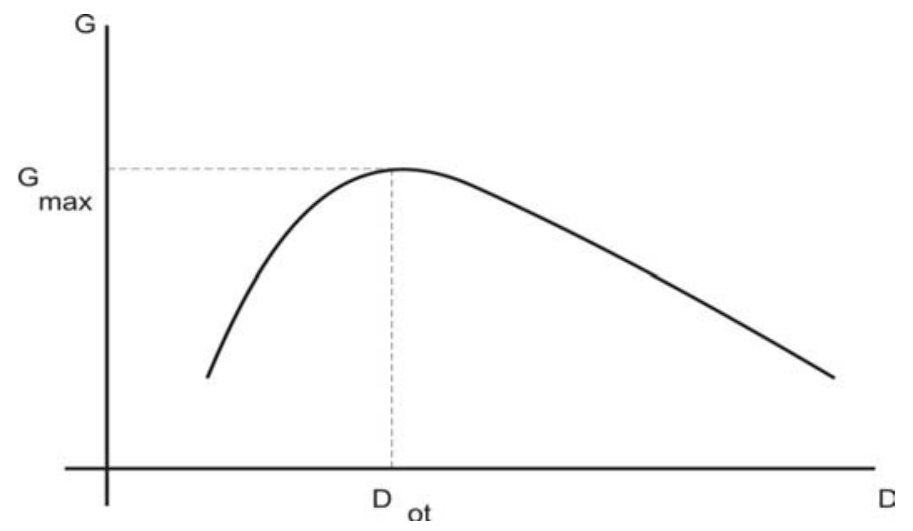

\section{SituAÇão FISCAL APÓs O PEC}

Após a entrada em vigor do Pacto de Estabilidade e Crescimento, podem ser percebidas três situações. A primeira acontece quando o valor do gasto governamental que torna máxima a utilidade do Estado-membro é menor do que o valor limite do gasto conforme o PEC, que será chamado de

1 A função $U$ é estritamente côncava. 
$G_{\text {lim }}$. Neste caso, não há conflito, pois o país está executando a despesa ideal sem entrar em choque com a União Européia $\left(G_{\max }<G_{\text {lim }}\right)$.

Figura 2 - Situação 1: $G_{\max }<G_{\text {lim }}$

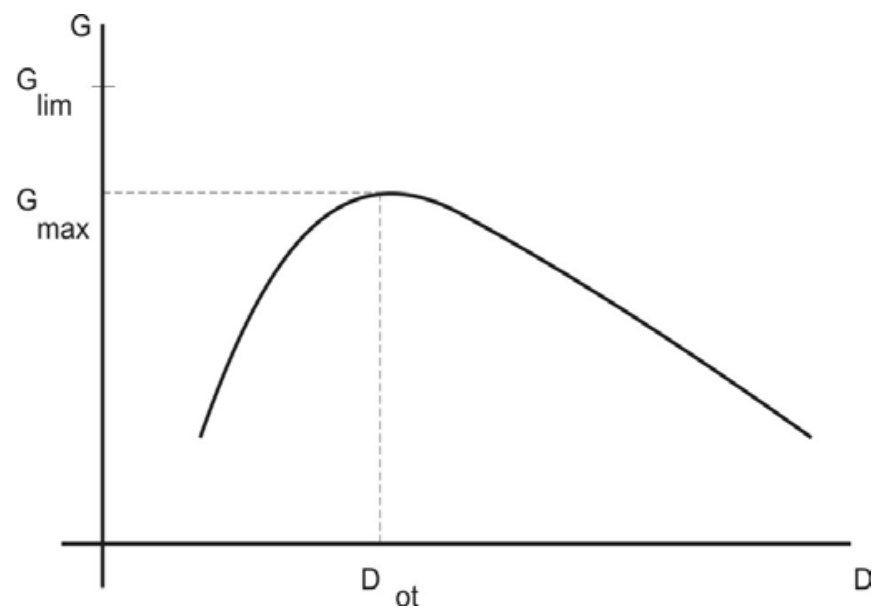

A segunda situação ocorre quando o gasto ótimo supera o limite estabelecido, $G_{\max }>G_{\text {lim }}$, e o Estado-membro opta por pagar a sanção $(S)$ imposta pelo Conselho de Ministros devido ao déficit excessivo, pois ainda assim sua utilidade será maior do que ajustar-se ao gasto imposto pelo PEC. ${ }^{2}$ Neste caso, a instituição da sanção não surte o efeito desejado pela União Européia, uma vez que o país, mesmo pagando a multa, ainda terá mais recursos para gastar do que o disponível se aceitasse o $\operatorname{PEC}\left(G_{\max }-S>G_{\text {lim }}\right)$.

Figura 3 - Situação 2: $G_{\max }-S>G_{l i m}$

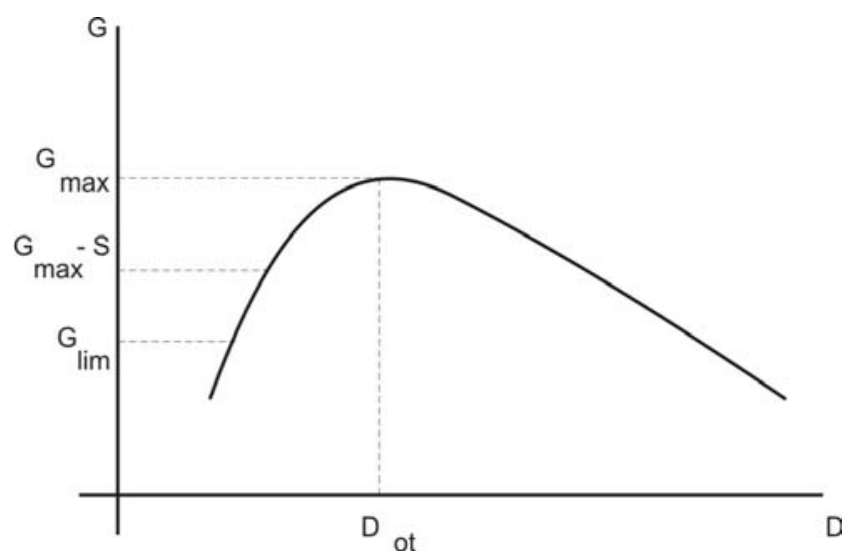

Por fim, a terceira situação acontece quando o país não está disposto a ser apenado com a sanção, pois isto lhe acarretará grande desutilidade, mesmo quando se considera um benefício político-social $C^{3}$ advindo do fortalecimento de sua imagem interna em decorrência da afronta ao bloco. Este benefício ocorre porque o governante sinaliza à sua população a preocupação com

2 Relativamente à questão intertemporal, por simplificação, considera-se que a sanção é paga no mesmo exercício em que acontece o déficit.

3 Para simplificar a análise, trata-se o parâmetro $C$ em termos equivalentes a gasto: $U(G+C)$. Na situação 2, também existe esse benefício político-social; no entanto, foi omitido por não interferir na análise. 
o crescimento econômico a despeito das exigências do Pacto $\left(G_{\max }-S+C<G_{\text {lim }}<G_{\text {max }}\right)$. Neste caso, surge espaço para o comportamento estratégico por parte da União Européia, uma vez que o Estado-membro somente se sujeitará ao limite de gasto imposto pelo PEC se esperar sofrer a sanção caso contrário. Como esta terceira situação é a mais interessante do ponto de vista estratégico, as seções seguintes se atêm a ela mais detalhadamente.

Figura 4 - Situação 3: $G_{\max }-S+C<G_{\text {lim }}<G_{\max }$

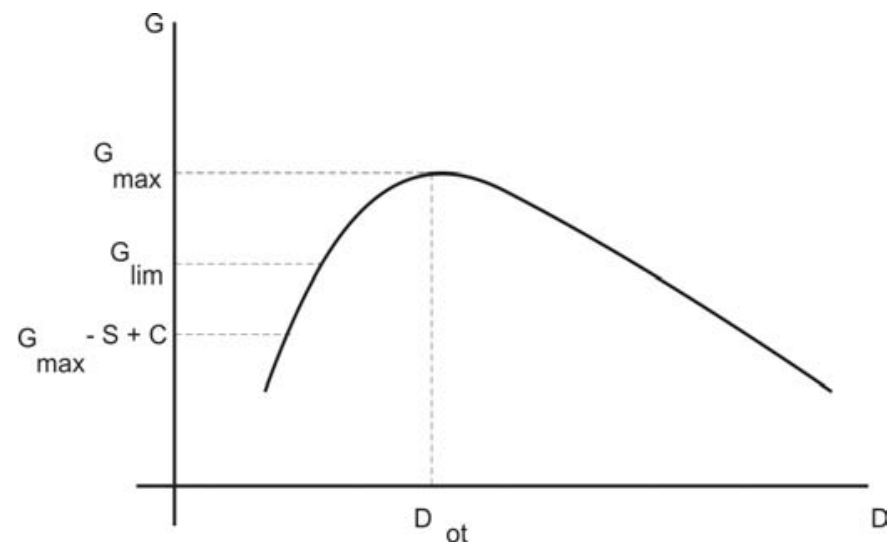

\subsection{Jogo, com informação completa, entre um país e a União Européia}

Considere-se a terceira situação estudada na seção anterior, ou seja, valem as seguintes desigualdades: ${ }^{4}$

$$
G_{\max }-S+C<G_{\text {lim }}<G_{\max }
$$

Neste jogo, o Estado-membro $(\mathrm{X})^{5}$ tem a opção de reduzir o déficit excessivo, promovendo apenas o gasto público ajustado $G_{\text {lim }}$ (estratégia $r$ ), ou não tomar medidas para diminuir o déficit, não se sujeitando às deliberações do Conselho de Ministros (estratégia nr). A União Européia (Y), por meio do Conselho de Ministros, pode aplicar a sanção (estratégia a) ou não (estratégia na). Caso a sanção seja aplicada, o país despenderá a multa $S$, mas receberá um beneficio político-social $C$, uma vez que sua imagem interna ficará fortalecida pela demonstração de se preocupar com o crescimento econômico. Por outro lado, a União Européia, ao optar por sancionar o Estado-membro, receberá o valor de $S,{ }^{6}$ mas também arcará com um custo político-social $\lambda$, pois resultará numa instabilidade do bloco por exigir uma medida mediante coação. Em contrapartida, se a União Européia decidir não aplicar a sanção, o Estado-membro continuará praticando o gasto ótimo $G_{\max }$ (com déficit excessivo) e a União Européia incorrerá num custo político $\mu$, já que haverá uma indisposição da União com aqueles países que promoveram o ajuste.

A forma extensiva do jogo com as conseqüências correspondentes encontra-se apresentada a seguir:

4 Uma inferência direta dessa expressão é que $S>C$, ou seja, o custo fiscal da sanção é maior que o benefício político do gasto excessivo.

5 Primeiramente, os países são tratados de forma homogênea. A partir da seção 3.3, os Estados-membros são considerados heterogêneos.

6 De fato, a sanção consiste primeiramente em um depósito não remunerado. No entanto, considera-se, por simplificação, que a União Européia se apropria definitivamente de $S$. 


\section{Figura 5}

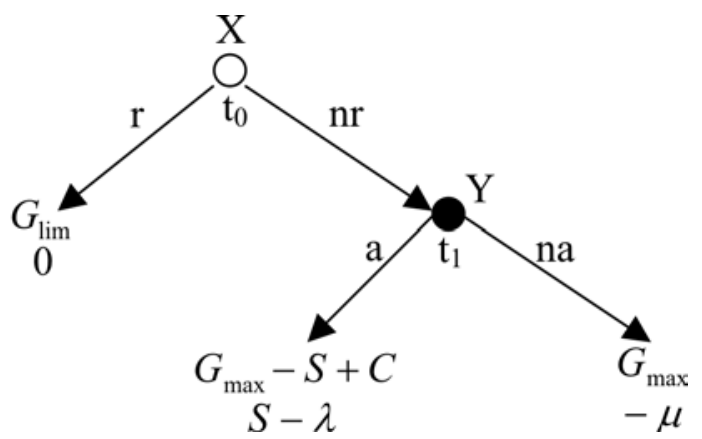

O jogo de informação completa será resolvido por indução retroativa, determinando-se primeiramente a decisão ótima da União Européia no nó $\mathrm{t}_{1}$ para depois encontrar a escolha ótima do Estado-membro em $t_{0}$, dada a escolha futura da União Européia. Para tanto, serão considerados dois ambientes, de acordo com os parâmetros do jogo.

Ambiente 1: $S-\lambda>-\mu \Leftrightarrow S>\lambda-\mu$

Observe-se que o lado esquerdo da última desigualdade em (3) agrupa os efeitos econômicos, enquanto o lado direito reflete o custo político líquido associado à sanção. Neste ambiente, como o retorno econômico da União Européia é maior do que o custo político quando ela resolve multar o país deficitário, ela escolherá em $\mathrm{t}_{1}$ aplicar a sanção (estratégia a).

O Estado-membro, por sua vez, prevendo que sofrerá a medida repressiva, decide reduzir seu déficit (estratégia r), ajustando-se ao Pacto de Estabilidade e Crescimento, haja vista estar valendo a desigualdade (2).

O equilíbrio resultante é (a,r) cujos pay-offs correspondentes são $G_{\max }-S+C$ e $S-\lambda$, para o Estado-membro e a União Européia, respectivamente.

Ambiente 2: $S-\lambda>-\mu \Leftrightarrow S>\lambda-\mu$

Neste segundo ambiente, o retorno econômico é pequeno comparado ao custo político de se aplicar a sanção; logo, a União Européia optará por não multar o país deficitário (estratégia na).

Antecipando o comportamento da União Européia, o Estado-membro decidirá não desviar do seu gasto ótimo $\left(G_{\max }\right)$, promovendo o déficit excessivo (estratégia nr).

Neste ambiente, o bloco econômico corre sérios riscos, pois os países possuem incentivos para não cumprir os pactos assinados. Como isso está acontecendo num caso em que $G_{\max }-S+C<G_{\text {lim }}$, bastaria que houvesse garantia de punição para que o Estado-membro se ajustasse ao PEC.

Há que se questionar, no entanto, a hipótese de informação completa. De fato, se é verdade que a multa $S$ é de conhecimento comum, os custos políticos $\lambda$ e $\mu$ são tipicamente informação privada da União Européia. Portanto, torna-se mais realista o estudo de um modelo de informação incompleta em que o país deficitário desconhece os verdadeiros custos políticos para a União associados às suas possíveis estratégias. 


\subsection{Jogo com informação incompleta: dois tipos de bloco econômico}

Considere-se novamente o jogo apresentado na Figura 5. Se o país detiver informação completa sobre os custos envolvidos num confronto com o bloco, então um dos equilíbrios estudados anteriormente será realizado. Quando o custo político-social de aplicar a sanção é baixo para a União Européia ( $\lambda$ baixo), tem-se um bloco econômico forte, no sentido de que adotará medida repressiva se necessário. Nesta situação, o Estado-membro se ajustará, de forma a evitar retaliação. Alternativamente, quando o custo político-social de aplicar a sanção é muito alto para a União Européia ( $\lambda$ alto), tem-se um bloco econômico fraco, no sentido de que não adotará medida repressiva. Nesta situação, o Estado-membro poderá despender otimamente, sem medo de sofrer retaliação.

No entanto, na realidade, o país deficitário não sabe ao certo com que tipo de União Européia está lidando. Ou seja, o parâmetro $(\lambda)$ é de conhecimento privado da União Européia, sendo que o Estado-membro possui informação incompleta sobre esse parâmetro, que pode assumir dois valores distintos, $\lambda^{f}$ ou $\lambda^{F}$.

A União Européia do tipo fraco, ou União Européia fraca, é aquela cujo parâmetro $\lambda$ assume um valor $\lambda^{f}$ alto, de forma que:

$$
\lambda^{f}-\mu>S
$$

Já a União Européia do tipo forte, ou União Européia forte, é aquela cujo parâmetro $\lambda$ assume um valor $\lambda^{F}$ baixo, de forma que:

$$
\lambda^{F}-\mu<S
$$

Apesar de a União Européia conhecer seu tipo, o Estado-membro sabe apenas que o bloco econômico é do tipo forte $\left(\lambda^{F}\right)$ com probabilidade $\kappa$ ou do tipo fraco $\left(\lambda^{f}\right)$ com probabilidade $1-\kappa$. Conforme o jogo desenvolvido na seção 3.1, a União Européia fraca, denotada por $\mathrm{Y}^{\mathrm{f}}$, não aplicará a sanção ao país excessivamente deficitário. Por outro lado, a União Européia forte, denotada por $\mathrm{Y}^{\mathrm{F}}$, sempre imporá a sanção ao Estado-membro que apresentar déficit excessivo.

Considerando os dois tipos de bloco econômico, pode-se construir o seguinte jogo, com informação incompleta.

Por ser um jogo de informação incompleta, procura-se determinar seus equilíbrios bayesianos perfeitos. ${ }^{8}$ Por racionalidade seqüencial, a União Européia forte sempre escolherá aplicar a sanção $\left(\mathrm{Y}^{\mathrm{F}}: \mathrm{a}\right)$, caso o Estado-membro não reduza seu déficit. Em contrapartida, a União Européia fraca sempre deixará de adotar qualquer medida punitiva ( $\left.\mathrm{Y}^{\mathrm{f}}: \mathrm{na}\right)$ quando se deparar com um país que esteja descumprindo o Pacto. Resta saber qual será a atitude do país que está com déficit excessivo.

7 De fato, o tipo da União Européia é dado por $(\lambda-\mu)$, mas, por simplicidade, supõe-se $\mu$ constante e concentra-se a especificidade da União Européia no parâmetro $\lambda$.

8 O Equilíbrio Seqüencial envolve atualização de crenças fora do caminho de equilíbrio. Nesse jogo, como não há conjunto de informação fora do caminho de equilíbrio, o Equilíbrio Seqüencial coincide com o Equilíbrio Bayesiano Perfeito. 
Figura 6 - Jogo entre União Européia e Estado-membro com informação incompleta sobre a União Européia

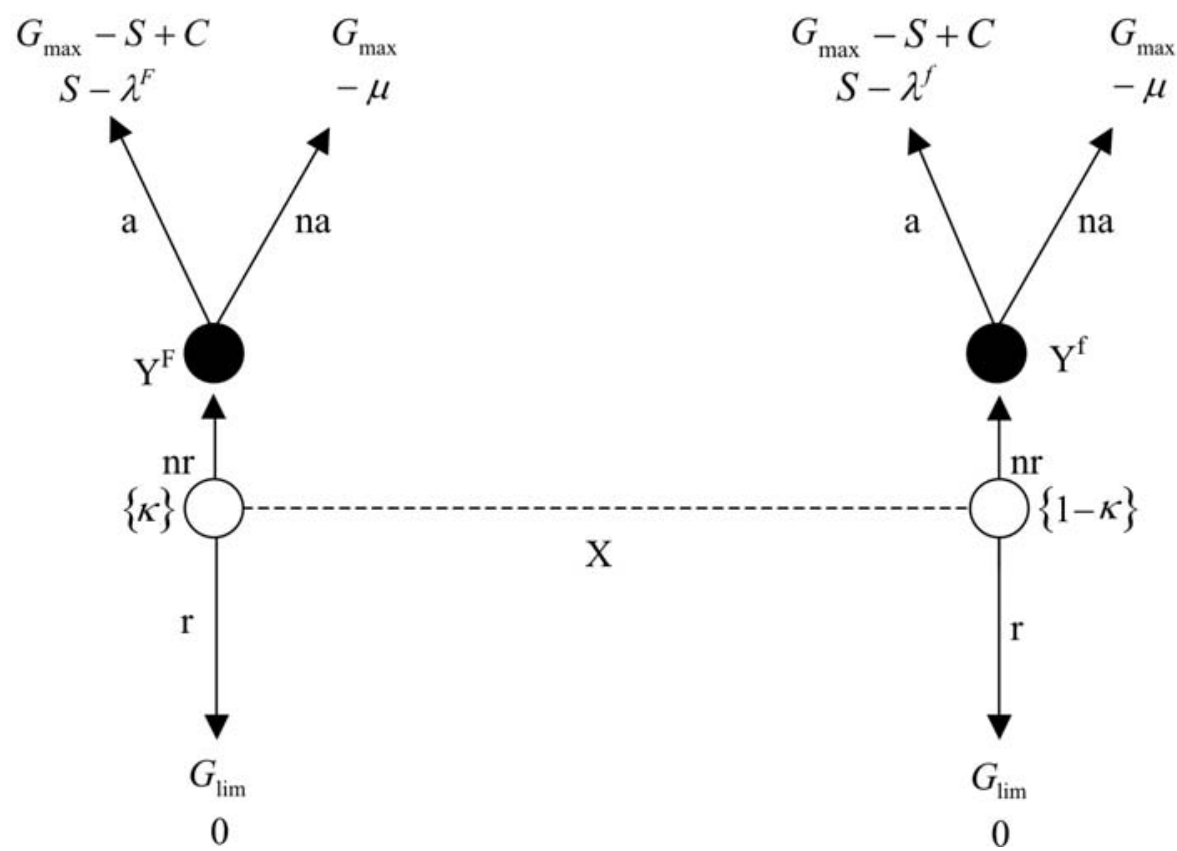

O Estado-membro tem duas opções: reduzir seu déficit (estratégia r) ou não reduzi-lo e manter o gasto ótimo (estratégia nr). Por consistência bayesiana, a crença do Estado-membro de estar lidando com uma União Européia forte é a probabilidade ex-ante $\kappa$. Considerando as escolhas da União Européia, as utilidades esperadas do Estado-membro (X) são:

$$
\begin{aligned}
& U E(X / r)=G_{\text {lim }} \\
& U E(X / n r)=\kappa\left(G_{\max }-S+C\right)+(1-\kappa) G_{\max }=G_{\max }+\kappa(C-S)
\end{aligned}
$$

Para $\kappa=0$ (o país tem certeza de que se trata de uma União Européia fraca), considerando a desigualdade (2), tem-se que a escolha do Estado será não reduzir o déficit excessivo. Por outro lado, se $\kappa=1$ (o país tem certeza de que a União Européia é forte), o Estado escolherá reduzir o déficit. Ou seja, a opção a ser tomada pelo Estado depende da magnitude de $\kappa$. Comparando as expressões (5) e (6), encontra-se o valor de $\kappa$ que faz a fronteira das duas opções do Estado-membro.

Para tanto, seja $\kappa_{0}=\frac{G_{\max }-G_{\text {lim }}}{S-C}$.

Pela hipótese (2), sabe-se que $G_{\max }-G_{\text {lim }}<S-C$ e $G_{\max }-G_{\text {lim }}>0$. Logo, $\kappa_{0} \in(0,1)$.

Assim:

i. se $\kappa>\kappa_{0}$, o país escolherá a estratégia r;

ii. se $\kappa<\kappa_{0}$, o país escolherá a estratégia nr. 
Isso significa que a escolha do Estado-membro depende de uma reputação prévia, $\kappa$, conquistada pela União Européia que influi as crenças dos países a respeito do tipo do bloco econômico. ${ }^{9}$ Por isso, é tão importante que a União Européia mantenha uma posição firme com relação aos acordos pactuados, de forma a garantir um conceito de forte por parte dos integrantes do bloco e desestimulá-los a desrespeitar os tratados, conforme será visto nas próximas seções.

\subsection{Jogo com informação incompleta para ambos os jogadores}

A solução anterior é válida para uma situação em que há apenas um tipo de país; no entanto, é natural que a União Européia detenha informação incompleta a respeito dos Estados-membros. Ou seja, assim como o Estado não conhece o tipo da União Européia, o Bloco também não tem informação sobre o parâmetro $C$ relativo ao Estado-membro.

Assim, considera-se agora que existem dois tipos de países. O Estado-membro dito forte, caracterizado pela notação $C^{F}$, é aquele cujo benefício político-social $C$, por não ter reduzido o déficit, é alto o suficiente, de forma que:

$$
C^{F}>S-\left(G_{\max }-G_{l i m}\right)
$$

O Estado-membro dito fraco, cujo benefício é representado por $C^{f}$, é aquele em que o proveito político-social $C$, por não ter reduzido o déficit, é pequeno o suficiente, de forma que:

$$
C^{f}<S-\left(G_{\max }-G_{l i m}\right)
$$

A União Européia não observa o tipo do Estado-membro, sabendo apenas que é do tipo forte com probabilidade $v$, sendo então do tipo fraco com probabilidade $1-v$.

Dessa forma, considerando os dois tipos de países e os dois tipos de blocos econômicos, ${ }^{10}$ podese construir o jogo com informação incompleta apresentado na Figura 7.

Nesse caso, a União Européia forte $\left(\mathrm{Y}^{\mathrm{F}}\right)$ continua a ter como estratégia dominante aplicar a sanção, enquanto a União Européia fraca $\left(\mathrm{Y}^{\mathrm{f}}\right)$ optará sempre por não aplicá-la.

Resta saber quais serão as escolhas dos Estados-membros forte e fraco. Relativamente ao país forte $\left(\mathrm{X}^{\mathrm{F}}\right)$, temos as seguintes utilidades esperadas:

$$
\begin{aligned}
& U E\left(\mathrm{X}^{F} / r\right)=G_{\mathrm{lim}} \\
& U E\left(\mathrm{X}^{F} / n r\right)=\kappa\left(G_{\max }-S+C^{F}\right)+(1-\kappa) G_{\max }=G_{\max }+\kappa\left(C^{F}-S\right)
\end{aligned}
$$

Como para o país forte, $C^{F}>S-\left(G_{\max }-G_{\text {lim }}\right)$, e conhecendo a desigualdade $G_{\text {lim }}<G_{\max }$, temse que $U E\left(\mathrm{X}^{F} / n r\right)>U E\left(\mathrm{X}^{F} / r\right)$; isto significa que o Estado-membro forte possui uma estratégia dominante, que é escolher nr, ou seja, o país forte não se sujeitará às deliberações do Conselho de Ministros e não reduzirá seu déficit, independentemente de pagar ou não a sanção $S$.

Com relação ao Estado-membro fraco, as utilidades esperadas são:

$$
U E\left(\mathrm{X}^{f} / r\right)=G_{\lim }
$$

9 Existe ainda um equilíbrio bayesiano perfeito em estratégias mistas unicamente no caso em que $\kappa=\kappa_{0}$, pois nesta situação, o Estado-membro é indiferente entre $\mathrm{r}$ e nr. Neste caso, o país escolhe $\mathrm{r}$ com qualquer probabilidade $\pi \in[0,1]$ e escolhe $\mathrm{nr}$ com a probabilidade $1-\pi$. Tal equilíbrio não é enfatizado aqui por se tratar de uma situação muito particular. De qualquer forma, esses são os únicos equilíbrios bayesianos perfeitos do jogo. Agradecemos a um parecerista anônimo por chamar a atenção para esse equilíbrio com estratégias mistas.

10 Neste modelo, supõe-se que tipos dos jogadores são independentes. 


$$
U E\left(\mathrm{X}^{f} / n r\right)=\kappa\left(G_{\max }-S+C^{f}\right)+(1-\kappa) G_{\max }=G_{\max }+\kappa\left(C^{f}-S\right)
$$

Analogamente ao item 3.2, existe um valor de $\kappa$ que faz a divisória entre as escolhas do país fraco. Seja $\kappa_{0}=\frac{G_{\max }-G_{\lim }}{S-C^{f}} \in(0,1)$, então: ${ }^{11}$

i. se $\kappa>\kappa_{0}, \mathrm{X}^{\mathrm{f}}$ escolherá a estratégia r;

ii. se $\kappa<\kappa_{0}, \mathrm{X}^{\mathrm{f}}$ escolherá a estratégia nr.

Figura 7 - Jogo entre a União Européia e o Estado-membro com informação incompleta bilateral

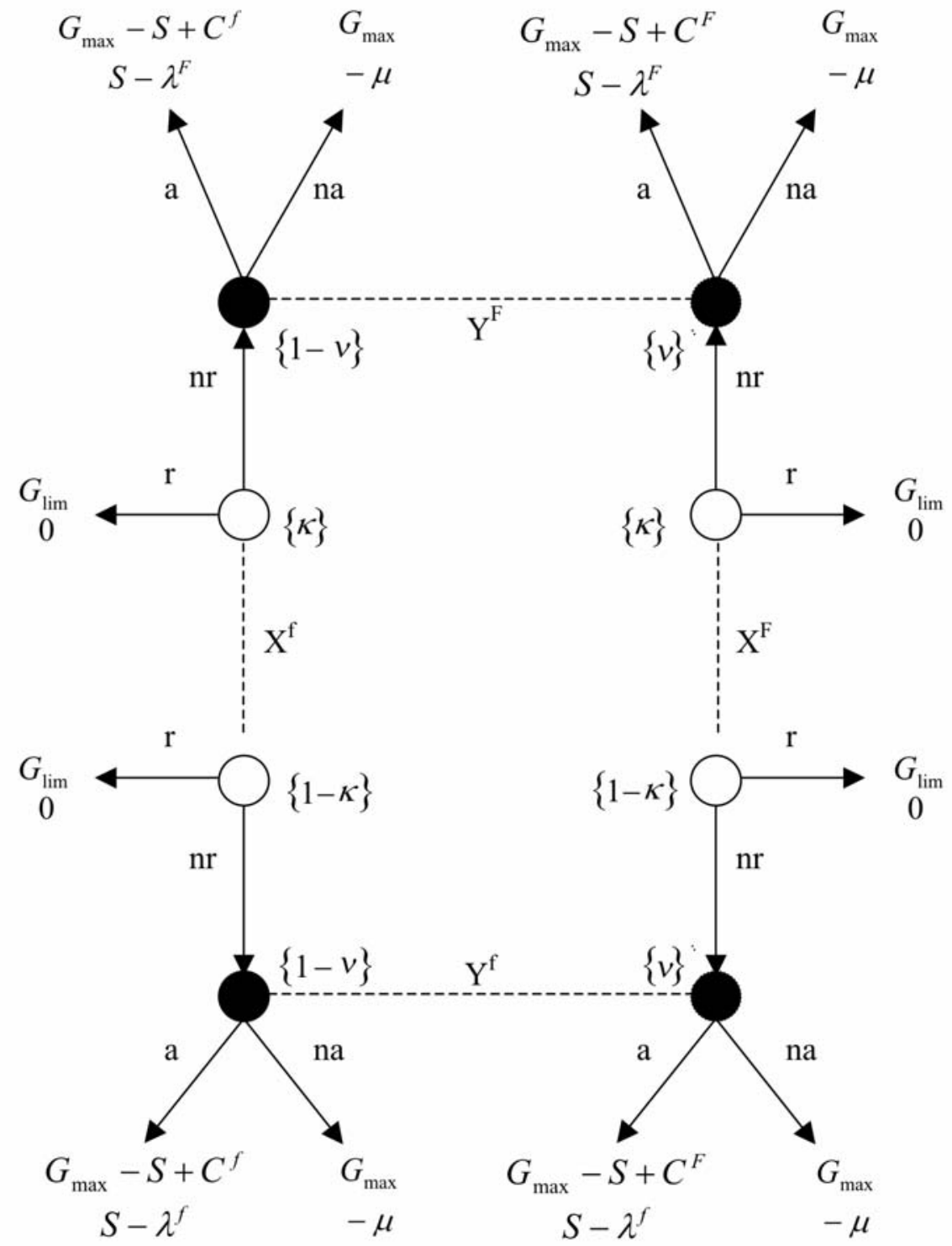

11 Novamente, existe um equilíbrio bayesiano perfeito em estratégias mistas em que o país fraco escolhe $\mathrm{r}$ com qualquer probabilidade $\pi \in[0,1]$ e escolhe nr com a probabilidade $1-\pi$, no caso em que $\kappa=\kappa_{0}$. Tal equilíbrio não é enfatizado aqui por se tratar de uma situação muito particular. Estes são os únicos equilíbrios bayesianos perfeitos do jogo. 
Em suma, o país forte possui estratégia dominante e nunca estará disposto a reduzir seu déficit excessivo. Já o país fraco tomará sua decisão conforme seja sua crença a respeito do tipo da União Européia. Novamente, isto ressalta a importância, para o bloco econômico, em construir uma reputação de que defenderá o Pacto a qualquer custo, motivando, assim, os Estados fracos a manterem suas finanças em ordem. Este argumento será tornado preciso na próxima subseção.

\subsection{Jogo dinâmico com informação incompleta envolvendo dois países}

Considere agora a decisão da União Européia em um contexto dinâmico em que esta lida com dois estados seqüencialmente. Seja, assim, um jogo envolvendo dois países e dois períodos. No primeiro período, o país 1 toma sua decisão quanto à redução do déficit excessivo. A União Européia, por sua vez, decide se aplica sanção ao país ou não caso ele não tenha cumprido o Pacto. No segundo período, o país 2 observa o resultado da interação entre o país 1 e o bloco econômico e, a seguir, decide se reduz ou não o seu próprio déficit. A União Européia reage e delibera sobre a punição desse outro Estado-membro, se for o caso.

Essa seqüência pode ser representada por duas cópias da Figura 7. Na primeira, tem-se a interação entre o país 1 e a União Européia. Na segunda cópia, jogada logo em seguida à primeira, apresenta-se o bloco econômico interagindo com o segundo país. Note que cada Estado-membro deriva sua utilidade em período distinto. Com relação à União Européia, que aufere utilidade nos dois períodos, considera-se, por simplicidade, um fator de desconto intertemporal unitário.

Além do fato de cada período tratar de países distintos, outra diferença é que há uma natural atualização das crenças no segundo período relativamente ao tipo dos jogadores envolvidos no primeiro período.

Seja a crença ex-ante $\kappa$ do país a respeito do tipo do bloco econômico e suponha que $\kappa>\kappa_{0}{ }^{12}$ Neste caso, somente o Estado-membro forte descumprirá o Pacto. O Estado-membro fraco seguirá as determinações de ajuste fiscal, por acreditar que existe uma elevada probabilidade de a União Européia ser forte e enfrentá-la acarretaria uma grande perda. Assim, o bloco econômico inicialmente se beneficia de uma crença ex-ante $\kappa$ alta.

Como os dois países em questão realizam seus jogos seqüencialmente, haverá uma atualização, no segundo período, da crença sobre o tipo da União Européia, sempre que possível. Por exemplo, se no primeiro período um bloco fraco $\left(\lambda=\lambda^{f}\right)$ se defrontar com um país forte e decidir não aplicar sanção ao Estado-membro deficitário, isto fará com que o tipo da União Européia seja revelado como fraco (esta revelação é inevitável porque a União Européia forte sempre aplica a sanção). Em conseqüência, no segundo período a crença do país 2 sobre o tipo do bloco econômico é atualizada de $\kappa$ para $\kappa_{2}=0$. Portanto, o país 2 sabe que está enfrentando uma União Européia fraca, e então promoverá seu gasto ótimo (com déficit excessivo), qualquer que seja seu tipo, isto é, mesmo sendo fraco.

Em contrapartida, a União Européia tem a oportunidade estratégica de não revelar seu tipo e tentar criar uma reputação de forte para influenciar o comportamento do país fraco no segundo período.

Um bloco econômico fraco tem duas opções ao se deparar com um país deficitário que não quer se ajustar ao Pacto de Estabilidade e Crescimento (PEC). Pode não aplicar a sanção e, automaticamente, revelar seu tipo, fazendo com que o outro país no segundo período atualize sua crença para $\kappa=0$ e também deixe de cumprir o PEC.

12 Esta hipótese será usada durante toda a seção. 
Por outro lado, se a União Européia fraca multar o Estado-membro deficitário, ela arcará com um elevado custo político-social, mas não terá seu tipo revelado. Assim, no segundo período, um país fraco manterá sua crença original e reduzirá o déficit.

Por ser um jogo dinâmico de informação incompleta, busca-se o Equilíbrio Bayesiano Perfeito (EBP). Para tanto, adiciona-se a seguinte hipótese:

$$
v<2-\frac{\lambda^{f}-S}{\mu}
$$

A expressão acima diz que a União Européia estima que a probabilidade (v) de estar lidando com um país forte é suficientemente baixa. Ou seja, essa hipótese tornará interessante para a União Européia fraca fazer-se passar por forte para influenciar o comportamento do Estado-membro fraco no segundo período.

A solução do jogo passa novamente pela observação de que um país forte $\left(\mathrm{X}^{\mathrm{F}}\right)$ tem por estratégia dominante não reduzir o déficit, e um bloco forte $\left(\mathrm{Y}^{\mathrm{F}}\right)$ tem por estratégia dominante a aplicação da sanção em qualquer país que descumpra o PEC em qualquer dos dois períodos. Já a União Européia fraca $\left(\mathrm{Y}^{\mathrm{f}}\right)$ tem por estratégia dominante no segundo período não executar medidas punitivas. Finalmente, a decisão do Estado-membro fraco $\left(\mathrm{X}^{\mathrm{f}}\right)$, no segundo período, dependerá de sua crença $\kappa=\kappa_{2}$ atualizada pelo critério de Bayes: se $\kappa_{2}<\kappa_{0}$, $\mathrm{X}^{\mathrm{f}}$ escolherá não reduzir o déficit e se $\kappa_{2}>\kappa_{0}, \mathrm{X}^{\mathrm{f}}$ se ajustará ao PEC, reduzindo seu déficit.

Resta então determinar a estratégia ótima da União Européia fraca no primeiro período, considerando que esta decisão poderá influenciar as crenças do Estado fraco no segundo período. Assim, as utilidades esperadas da União Européia fraca, quando o primeiro país não reduz o déficit, estão descritas a seguir:

$$
\begin{aligned}
& U E\left(Y^{f} / a\right)=\left(S-\lambda^{f}\right)+v(-\mu)+(1-v) \cdot 0=S-\lambda^{f}-\mu \nu \\
& U E\left(Y^{f} / n a\right)=(-\mu)+v(-\mu)+(1-v) \cdot(-\mu)=-2 \mu
\end{aligned}
$$

Nas expressões (8) e (9), o primeiro termo reflete a utilidade percebida no primeiro período, ao passo que os dois termos seguintes calculam a utilidade esperada no segundo período.

Considerando a hipótese (7), pode-se concluir que a $U E\left(Y^{\mathrm{f}} / \mathrm{a}\right)>\mathrm{UE}\left(\mathrm{Y}^{\mathrm{f}} / \mathrm{na}\right)$. Assim, existe um equilíbrio bayesiano perfeito agregador desse jogo, que acontece quando a União Européia do tipo fraco aplica a sanção ao país deficitário, mesmo sabendo que isto lhe causará um prejuízo no primeiro período, de forma a induzir um país fraco a não gerar déficit excessivo no segundo período.

A caracterização desse equilíbrio bayesiano perfeito é a seguinte. Um Estado-membro forte sempre descumprirá o pacto. Um Estado-membro fraco cumprirá o pacto no primeiro período, e no segundo período também o cumprirá a menos que observe, no primeiro período, um Estado descumprir o pacto e não ser punido pela União Européia. Uma União Européia forte sempre punirá qualquer Estado-membro que descumpra o pacto em qualquer período. Finalmente, uma União fraca punirá um Estado-membro que descumpra o pacto no primeiro período, de forma a manter uma reputação de forte, mas não punirá um Estado-membro gastador no último período. As crenças consistentes no primeiro período são $\kappa_{1}=\kappa$ e, no segundo período, $\kappa_{2}=\kappa$ se não houve descumprimento no primeiro período ou se houve descumprimento seguido de sanção no período 1. Finalmente, $\kappa_{2}=0$ caso haja descumprimento do pacto sem a correspondente sanção no período 
1. Portanto, no equilíbrio encontrado, a ação da União Européia no primeiro período é não informativa.

Assim, o equilíbrio apresentado sugere uma ação a ser tomada pelo bloco econômico: punir qualquer país que se desequilibre fiscalmente, mesmo que isso envolva a manutenção custosa de reputação, de forma a defender um bloco coeso com uma política macroeconômica uniforme. Note, no entanto, que para que o equilíbrio encontrado seja válido, é necessário que de alguma forma a União Européia já tenha construído uma reputação de forte, de maneira que os países estimem, no início do primeiro período, que $\kappa>\kappa_{0}$.

Vale observar que se as hipóteses $\kappa>\kappa_{0}$ e a expressão (7) forem alteradas, poderão surgir outros equilíbrios. No entanto, o ponto que queremos enfatizar é a possibilidade do uso estratégico da reputação por parte da União Européia. ${ }^{13}$

\section{CONSIDERAÇÕES ACERCA DAS INSTITUIÇÕES EUROPÉIAS: UMA EXTENSÃO}

Na modelagem apresentada a partir da seção 3.1 foram caracterizadas as estratégias do bloco econômico com o jogador intitulado de União Européia. No entanto, existem pelo menos duas instituições que têm um papel marcante nas disputas entre os países e o bloco: a Comissão Européia e o Conselho de Ministros.

A Comissão Européia é o órgão técnico cujo objetivo é defender os interesses da União como um todo. Contudo, está somente autorizada a propor ações. As decisões sobre as iniciativas da Comissão são tomadas pelo Conselho de Ministros de cada área temática. Este último colegiado, pela sua própria composição, é um órgão político.

Essa diferenciação é que explica a discussão havida no caso da França e da Alemanha entre a Comissão Européia e o Conselho de Ministros, que teve de ser solucionada no Poder Judiciário Europeu, dando ganho de causa à Comissão. Resumidamente, após grande campanha do eixo franco-alemão para que seus sócios na União Européia compreendessem a difícil situação em que se encontravam, não sendo possível reduzir o déficit até 2005, o Conselho de Economia e Finanças da União Européia (ECOFIN), apesar da oposição de vários integrantes, como Espanha, Bélgica e Suécia e da Comissão Européia (que pretendia iniciar o processo para a aplicação da sanção), decidiu, em 25/11/2003, apenas pedir aos governos de Berlim e Paris um empenho político para enxugarem seus déficits.

Assim, pode ser mais adequado modelar a disputa entre Estados-membros e o bloco, separando o jogador União Européia em dois outros jogadores que representassem a Comissão e o Conselho de Ministros distintamente. A Comissão corresponderia ao jogador que no jogo original defende a manutenção do Pacto e que lá foi chamado de União Européia e teria a incumbência de sugerir ou não a aplicação da sanção. Por seu lado, o Conselho de Ministros confirmaria ou não a sugestão da Comissão.

Note que a Comissão continua tendo duas opções: ou ela nem inicia o procedimento de déficit excessivo com vistas à aplicação da multa (estratégia na) ou ela sugere a aplicação da sanção (estratégia a) e, neste caso, sua decisão deverá ser ou não ratificada pelo Conselho de Ministros.

As decisões, no âmbito do Conselho de Ministros, decorrem de negociações internas, que serão modeladas como um processo aleatório, em que as escolhas são aleatórias com probabilidades

13 Agradecemos a um parecerista anônimo por chamar a atenção para outros possíveis equilíbrios no jogo dinâmico. 
predeterminadas para cada país. Sendo, portanto, o Conselho de Ministros um jogador que apenas interfere nas ações dos outros agentes, não lhe é atribuído nenhum pay-off ao final desse jogo e, assim, pode ser interpretado como a Natureza (N).

O Conselho de Ministros (Natureza) pode concordar ou não com as medidas propostas pela Comissão. A estas duas opções atribuem-se probabilidades. Destarte, o Conselho confirma a aplicação da sanção para o país com probabilidade $\omega$, ou não concorda com a sugestão da Comissão, desautorizando-a a executar a multa, com probabilidade $1-\omega$.

Caso a Comissão sugira a sanção e o Conselho não a ratifique, ela terá que arcar com o custo político-social $\lambda$, por ter tentado exigir uma medida mediante coação, mas não se beneficiará do valor da multa $S$.

Figura 8 - Jogo entre um País, a Comissão Européia e o Conselho de Ministros

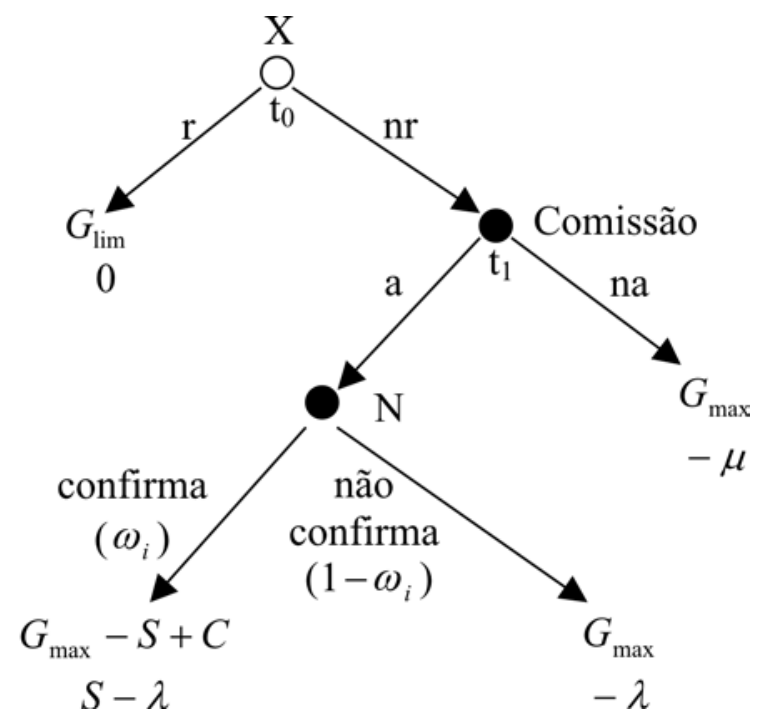

Resolvendo o jogo por indução retroativa, determina-se primeiramente a decisão ótima da Comissão. Se ela sugerir a sanção (estratégia a), seu pay-off esperado será:

$$
U E(\text { Comissão/a })=\omega(S-\lambda)+(1-\omega)(-\lambda)=\omega S-\lambda
$$

Se a Comissão optar por não tentar multar o país deficitário (estratégia na), seu pay-off será $(-\mu)$.

De forma análoga à seção 3.1, existem dois ambientes possíveis:

Ambiente 1: $\omega S-\lambda>-\mu \Leftrightarrow S>\frac{\lambda-\mu}{\omega}$

Ambiente 2: $\omega S-\lambda<-\mu \Leftrightarrow S<\frac{\lambda-\mu}{\omega}$

Novamente pode-se constatar nas desigualdades acima que o lado esquerdo agrupa os efeitos econômicos, enquanto o lado direito reflete o custo político líquido dividido pela probabilidade de o Conselho concordar com a Comissão. Esta probabilidade $\omega$ é justamente o que diferencia este jogo daquele apresentado na seção 3.1.

A divisão por $\omega$ no lado direito da desigualdade faz com que o custo político líquido esperado da aplicação da multa pela Comissão seja majorado, comparado com o modelo em que apenas 
existia o jogador União Européia. Isto significa que, na presença de um Conselho de Ministros que pode desautorizar as decisões da Comissão, esta será muito mais comedida no momento de propor uma sanção, tornando maior o incentivo dos Estados-membros em descumprirem o Pacto de Estabilidade e Crescimento. Ou seja, com a existência do Conselho de Ministros, caracterizado como uma instituição essencialmente política, mais difícil será a obtenção do equilíbrio que garanta a estabilidade, prejudicando a coesão do bloco.

\section{DEMAIS EXTENSÕES}

O modelo básico apresentado na Figura 5 pode ser estendido de várias formas sem comprometer os resultados encontrados.

Primeiramente, pode-se alterar o pay-off da União Européia para um valor maior que zero quando o Estado-membro optar por reduzir o déficit. Ou seja, a União Européia adquirirá uma utilidade positiva mesmo sem ter que jogar. Esta mudança aumentará os incentivos para que a União Européia tente manter a reputação de ser forte.

Outra extensão consiste em aplicar na utilidade da União Européia, relativamente ao modelo da seção 3.4, um fator de desconto intertemporal. Isto torna menos importante para o bloco o benefício obtido no segundo período com a construção de reputação. Ainda assim, se a União Européia fraca não descontar demasiadamente o futuro, continuará a ser de seu interesse aplicar a sanção ao país deficitário.

O jogo apresentado em 3.4 trabalha com apenas dois países; no entanto, o argumento é o mesmo quando existem $n$ países, usando-se indução retroativa. No penúltimo jogo (com o país $n-1$ ), a União Européia fraca, que não revelou seu tipo em nenhum dos períodos anteriores, decidirá aplicar a multa ao país deficitário desde que a condição (7) seja satisfeita. No antepenúltimo período, se a União Européia punir o Estado-membro deficitário, disciplinará o país fraco no período seguinte $(n-1)$ e manterá seu tipo em segredo. Assim, a União Européia terá um estímulo ainda maior para reter recursos de um estado forte inadimplente, sendo a condição (7) mais que suficiente para que a União Européia fraca mantenha esse comportamento. O raciocínio claramente se repete até o primeiro período.

Portanto, a mesma condição que garante a construção de reputação no modelo com dois Estados-membros também garante que um equilíbrio de reputação será atingido quando existirem $n$ Estados-membros.

\section{CONCLUSÃO}

Segundo avaliação da Comissão, a União Européia pode não alcançar as metas econômicas estabelecidas porque muitos países-membros mostram uma ineficiência preocupante na redução de seus déficits. Além disso, o Conselho de Ministros tomou decisões que recompensam em vez de punir quem desrespeita as normas estipuladas. A médio prazo, a não aplicação do Pacto de Estabilidade e Crescimento (PEC) poderá levar o bloco a uma alta das taxas de juros e à queda do crescimento.

Este estudo vem contribuir para tentar encontrar uma solução para essa situação, mostrando quais estratégias devem ser adotadas para que o PEC seja respeitado. 
Primeiramente, num jogo de informação completa, em que o valor da sanção supera a diferença entre a perda política do bloco (por ter um pacto funcionando mediante coação) e o custo político de não multar e se indispor com os outros Estados-membros, a União Européia estaria sempre disposta a aplicar a sanção quando o PEC fosse descumprido. Tal postura reprimiria alguns países de realizarem déficit excessivo. No entanto, se a diferença entre esses custos for grande, a União Européia não teria força para fazer o pacto ser cumprido, o que facilitaria uma situação de déficit nos países.

Quando se considera a possibilidade de o Conselho de Ministros divergir da Comissão Européia sobre a aplicação da sanção ao país deficitário, o resultado é que há uma maior dificuldade para que a multa seja implementada, aumentando os incentivos dos Estados-membros em não cumprirem o Pacto de Estabilidade e Crescimento.

Com informação incompleta, como o país não conhece o tipo de bloco econômico com o qual está lidando, ele pode vir a optar por reduzir seu déficit ou não, dependendo da sua crença sobre a disposição política da União, que pode ser forte ou fraca de acordo com o valor do custo político de promover uma sanção. Esse resultado leva ao caso mais interessante, um jogo de informação incompleta com mais de um país, podendo também ter dois tipos de Estados-membros, fortes e fracos, cuja classificação depende do valor do benefício advindo de uma afronta à União. Tal possibilidade abre espaço para que o bloco construa uma reputação de forte e disto se beneficie.

A principal conclusão a que se chega é que o bloco econômico, sob o comando da Comissão Européia e do Conselho de Ministros, deve ser forte e exigir o cumprimento dos acordos pactuados, mesmo que isto lhe imponha um custo. Se houver a sinalização, como já está acontecendo, de que a União Européia não tem disposição suficiente para aplicar a multa prevista e fazer com que os países-membros ajustem seus déficits, provavelmente haverá um descumprimento em cascata do Pacto de Estabilidade e Crescimento, o que poderá fazer ruir a União Econômica e Monetária. Esta possibilidade já toma corpo diante da recente previsão da Comissão Européia de que Itália, GrãBretanha, Holanda e Grécia descumpram o limite de déficit de 3\% do PIB até 2007.

\section{REFERÊNCIAS BIBLIOGRÁFICAS}

Bierman, H. S.; Fernández, L. Game theory with economic applications. 2a edição. Addison-Wesley Publishing Company, 1998.

Bugarin, M. S. Subnational debt renegotiation and elections: experimentation and reputation in the Brazilian fiscal federalism. Brazilian Review of Econometrics, v. 26, n. 1, p. 67-104, 2006.

Comissão Européia. A política fiscal na União Européia. Série: A Europa em Movimento. Luxemburgo: Serviço das Publicações Oficiais das Comunidades Européias, 2000.

. Stability and growth pact and fiscal surveillance. Disponível em: http://europa.eu.int/comm/ economy_finance/about/activities/sgp/main_en.htm, 16/01/2004.

Drazen, A. Political economy in macroeconomics. $2^{\text {a }}$ edição. New Jersey: Princeton University Press, 2002.

Fudenberg, D.; Tirole, J. Game theory. $3^{\text {a }}$ edição. Cambridge: The MIT Press, 1993.

Hagen, J.; Hallerberg, M.; Strauch, R. The design of fiscal rules and forms of governance in European Union countries. V Complutense Internacional Seminar On European Economy, 2004.

Kreps, D.; Wilson, R. Reputation and imperfect information. Journal of Economic Theory, 27, p. 253-79, 1982. 
Meneguin, F. B.; Bugarin, M. S. Reeleição e política fiscal: um estudo dos efeitos da reeleição nos gastos públicos. Economia Aplicada, v. 5, n. 3, p. 601-622, jul./set. 2001.

Milgrom, P.; Roberts, J. Predation, reputation and entry deterrence. Journal of Economic Theory, 27, p. 280-312, 1982.

Myerson, R. B. Game theory - analysis of conflict. Cambridge: Harvard University Press, 1991.

Nordhaus, W. The political business cycle. Review of Economic Studies, 42, p. 169-190, 1975.

Raoux, A.; Terrenoire, A. A Europa e Maastricht - guia prático para a Europa 93. Lisboa: Publicações Dom Quixote, 1993.

Rogoff, K. Equilibrium political budget cycles. American Economic Review, 80, p. 21-36, 1990.

Werneck, R. L. F. Federalismo fiscal e a política de estabilização no Brasil. Revista Brasileira de Economia, v. 49, n. 2, p. 375-390, abril/junho 1995. 